\title{
Selective Reagent Ion Mass Spectrometric Investigations of the Nitroanilines
}

\author{
David Olivenza-León, ${ }^{1}$ Chris A. Mayhew, ${ }^{1,2}$ Ramón González-Méndez ${ }^{1,3}$ (]) \\ ${ }^{1}$ Molecular Physics Group, School of Physics and Astronomy, University of Birmingham, Edgbaston, Birmingham, B15 2TT, UK \\ ${ }^{2}$ Institut für Atemgasanalytik, Leopold-Franzens-Universität Innsbruck, Rathausplatz 4, 6850, Dornbirn, Austria \\ ${ }^{3}$ Centre for Agroecology, Water and Resilience, Coventry University, Coventry, CV1 5FB, UK
}

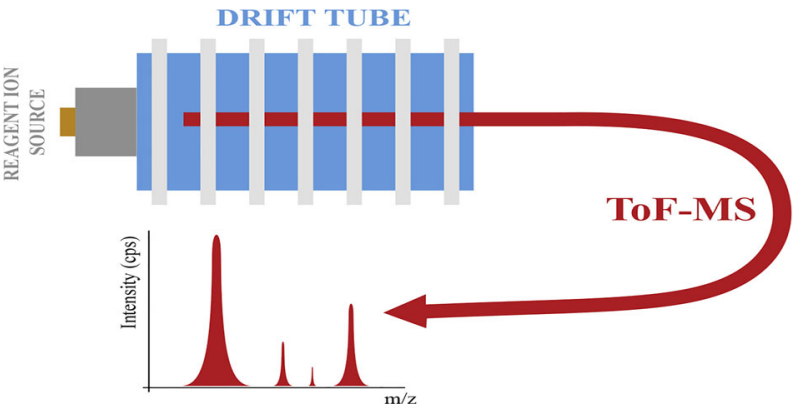

Abstract. This paper presents an investigation of proton and charge transfer reactions to 2-, 3- and 4-nitroanilines $\left(\mathrm{C}_{6} \mathrm{H}_{6} \mathrm{~N}_{2} \mathrm{O}_{2}\right)$ involving the reagent ions $\mathrm{H}_{3} \mathrm{O}^{+} \cdot\left(\mathrm{H}_{2} \mathrm{O}\right)_{n}(n=0,1$ and 2$)$ and $\mathrm{O}_{2}{ }^{+}$, respectively, as a function of reduced electric field (60-240 Td), using Selective Reagent lon-Timeof-Flight-Mass Spectrometry (SRI-ToF-MS). To aid in the interpretation of the $\mathrm{H}_{3} \mathrm{O}^{+} \cdot\left(\mathrm{H}_{2} \mathrm{O}\right)_{n}$ experimental data, the proton affinities and gas-phase basicities for the three nitroaniline isomers have been determined using density functional theory. These calculations show that proton transfer from both the $\mathrm{H}_{3} \mathrm{O}^{+}$ and $\mathrm{H}_{3} \mathrm{O}^{+} \cdot \mathrm{H}_{2} \mathrm{O}$ reagent ions to the nitroanilines will be exoergic and hence efficient, with the reactions proceeding at the collisional rate. For proton transfer from $\mathrm{H}_{3} \mathrm{O}^{+}$to the $\mathrm{NO}_{2}$ sites, the exoergicities are $171 \mathrm{~kJ} \mathrm{~mol}^{-1}(1.8 \mathrm{eV})$, $147 \mathrm{~kJ} \mathrm{~mol}^{-1}(1.5 \mathrm{eV})$ and $194 \mathrm{~kJ} \mathrm{~mol}^{-1}(2.0 \mathrm{eV})$ for 2-, 3- and 4-nitroanilines, respectively. Electron transfer from all three of the nitroanilines is also significantly exothermic by approximately $4 \mathrm{eV}$. Although a substantial transfer of energy occurs during the ion/molecule reactions, the processes are found to predominantly proceed via nondissociative pathways over a large reduced electric field range. Only at relatively high reduced electric fields (> $180 \mathrm{Td}$ ) is dissociative proton and charge transfer observed. Differences in fragment product ions and their intensities provide a means to distinguish the isomers, with proton transfer distinguishing 2-nitroaniline (2-NA) from 3- and 4-NA, and charge transfer distinguishing 4-NA from 2- and 3-NA, thereby providing a means to enhance selectivity using SRI-ToF-MS.

Keywords: Soft chemical i-mass spectrometry, Proton transfer reaction mass spectrometry, Nitroanilines, Explosives, Charge transfer

Received: 22 June 2019/Revised: 14 August 2019/Accepted: 15 August 2019/Published Online: 9 September 2019

\section{Research highlights}

- First investigations on the use of selective reagent ion mass spectrometry for nitroaniline isomers involving proton transfer and charge transfer reactions as a function of reduced electric field

- DFT calculations of the proton affinities and gas-phase basicities of the nitroanilines

- Identification of individual isomers through the manipulation of the ion chemistry

Correspondence to: Ramón González-Méndez;

e-mail: R.GonzalezMendez@bham.ac.uk;

Ramon.Gonzalez-Mendez@coventry.ac.uk

\section{Introduction}

elective Reagent Ion-Mass Spectrometry (SRI-MS) is a $\checkmark$ commonly used soft chemical ionisation technique used in a broad range of analytical fields and applications [1, 2]. These include environmental analysis, food science, atmospheric chemistry, health science, homeland security and breath analysis [312]. Its analytical technique is based on ion/molecule reactions in a controlled environment, namely a drift tube maintained at a constant pressure, temperature, humidity and fixed electric field. Commonly used reagent ions are $\mathrm{H}_{3} \mathrm{O}^{+}$and $\mathrm{O}_{2}{ }^{+}$, which react with traces of neutral organic molecules, injected directly into the drift tube of the instrument, usually with no pre-separation step. This allows for real-time analysis with a time resolution of approx. 
100 ms. These attributes make SRI-MS an ideal technique for detecting compounds that are only transiently (seconds) present in the drift tube. When $\mathrm{H}_{3} \mathrm{O}^{+}$is only used as the reagent ion, the technique is better known as Proton Transfer Reaction-Mass Spectrometry (PTR-MS) [1]. In this study, we investigated reactions involving both $\mathrm{O}_{2}^{+}$and $\mathrm{H}_{3} \mathrm{O}^{+}$, and hence, the term SRI-MS is more appropriate for the work presented here.

During the last 10 years, a large amount of work exploring the capabilities of SRI-MS for Homeland Security has been undertaken $[3-5,13-22]$. Two key objectives of this work are the following: (i) instrumental development for enhancing SRI-MS analytical performance (such as use of different reagent ions [16], new sample inlet methods [13], use of ion funnel for either enhanced sensitivity or selectivity $[18,23]$ and fast reduced electric field switching for enhanced selectivity [20]) and (ii) improving our knowledge of the underlying ion/molecule chemistry occurring within the reagent region of the analytical device.

A limitation with the selectivity of SRI-MS is associated with its capability to distinguish isomers. This is particularly true for proton transfer reactions, where often only the protonated parent ${ }^{1}$ is observed, but not necessarily so for other reaction processes such as charge transfer [24]. Here we present a SRI-MS study of the isomers of nitroanilines (2-, 3- and 4-nitroaniline) to ascertain whether they can be distinguished through the manipulation of the ion/chemistry. Another motivation for this study is that nitroanilines exhibit certain explosive characteristics, owing to their structure (aromatic ring with nitro functional group substituents). Therefore, these compounds represent a natural continuation of our SRI-MS studies of explosive compounds [3-5, 13, 15-22].

An additional interest is that nitroanilines are a family of chemical compounds used in the manufacture of dyes, pharmaceuticals and pesticides [25], so it is important to characterise them from a quality control need as different isomers have different properties and reactivities. They also exhibit a high toxicity, particularly the $[1,4]$ isomer [26], so it is relevant to develop analytical methods for quick, selective and reliable identification for environmental purposes.

Nitroanilines $\left(\mathrm{C}_{6} \mathrm{H}_{6} \mathrm{~N}_{2} \mathrm{O}_{2}, \mathrm{~m} / z\right.$ 138.04 Da (lightest isotopologue)) are a derivative of aniline, a commonly used precursor in the polymer industry, and hence is widespread in the environment [27]. Here we investigate whether the position of the nitro group plays a role in the ion/molecule processes. We present details on the product ion distributions resulting from the reactions of $\mathrm{H}_{3} \mathrm{O}^{+}$and $\mathrm{O}_{2}^{+}$. To aid in the interpretation of the experimental measurements involving the reagent ions $\mathrm{H}_{3} \mathrm{O}^{+} \cdot\left(\mathrm{H}_{2} \mathrm{O}\right)_{n}(n=0,1$ and 2$)$, quantum mechanical calculations have been undertaken to determine proton affinities and gas-phase basicities.

\footnotetext{
${ }^{1}$ Although revised IUPAC recommendations for terminology in mass spectrometry (Pure Appl. Chem., 2013, Vol. 85, No. 7, pp. 1515-1609) suggest replacing the term "parent" with "precursor", since for this work, ions are not mass selected, the term "precursor" is not appropriate. We note that "protonated parent" is commonly used within the PTR-MS community [1].
}

\section{Experimental Details}

\section{$S R I-M S$}

For this investigation, a Kore Technology Ltd. Series I Selective Reagent Ion-Time of Flight-Mass Spectrometer (SRIToF-MS) instrument was used, details of which been given elsewhere [1,28], and therefore only brief and pertinent details will be presented in this paper.

Proton Transfer Reaction Mode This mode exploits the proton transfer reaction of $\mathrm{H}_{3} \mathrm{O}^{+}$and, depending on the reduced electric field (the ratio of the electric field strength $(E)$ to the gas number density $(N)$ ) applied in the drift tube and the humidity, also protonated water clusters with molecules of interest $\mathrm{M}$ :

$\mathrm{H}_{3} \mathrm{O}^{+} \cdot\left(\mathrm{H}_{2} \mathrm{O}\right)_{n}+\mathrm{M} \rightarrow \mathrm{MH}^{+}+(n+1) \mathrm{H}_{2} \mathrm{O}$

where $n=0,1$ and 2 are the most important for our operational conditions (see Figure 1) but also (in low concentrations and only at low $E / N$ (less than approximately $100 \mathrm{Td}(1 \mathrm{Td}=$ $\left.\left.10^{-17} \mathrm{~V} \mathrm{~cm}^{2}\right)\right) n=3$. Proton transfer can be either nondissociative or spontaneously dissociative. Following nondissociative proton transfer, collisional induced dissociation may occur, with the probability of this increasing with increasing reduced electric field.

To produce the reagent ions, a series of ion-molecule processes (including three-body association) take place in a hollow cathode glow discharge, initiated by an electric discharge in water vapour and associated drift tube buffer gas that has diffused back into the ionisation source. The reagent ions that are generated in the ion source region are transferred into the drift tube by an applied voltage gradient. The relative intensities of the water reagent ions in the drift tube of the KORE instrument used as a function of $E / N$ are summarised in Figure 1, which illustrates that under our operating conditions,

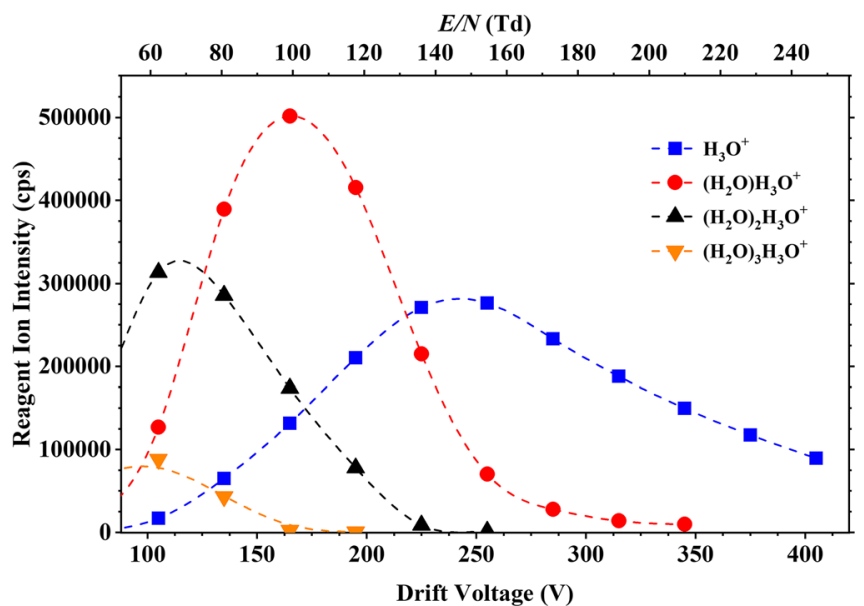

Figure 1. Ion intensities in counts per second (cps) of the water reagent ions $\left(\mathrm{H}_{3} \mathrm{O}^{+} \cdot\left(\mathrm{H}_{2} \mathrm{O}\right) \mathrm{n}, \mathrm{n}=0,1,2\right.$ and 3) recorded at the detector of the KORE SRI-ToF-MS as a function of reduced electric field (approximately 60-250 Td) 
only at relatively high $E / N$ values (greater than $140 \mathrm{Td}$ ) does $\mathrm{H}_{3} \mathrm{O}^{+}$become the dominant reagent ion.

Although $\mathrm{H}_{3} \mathrm{O}^{+}$(and associated protonated water clusters - depending on the value of the reduced electric field) dominates the reagent ion signal, other reagent ions are always present in the drift tube. These "impurity" reagent ions result from back diffusion of the buffer gas in the drift tube into the ion source. These reagent ions are those that cannot react with water, such as $\mathrm{O}_{2}{ }^{+}$. However, these are at very low concentrations. Under our experimental conditions, the intensity of was $\mathrm{O}_{2}{ }^{+}$was maintained below $0.5 \%$ of that of the $\mathrm{H}_{3} \mathrm{O}^{+}$signal.

The signal intensity of $\mathrm{H}_{3}{ }^{16} \mathrm{O}^{+}$is generally too large to be measured directly. Therefore, the signal intensity for the spectral line peaking at $\mathrm{m} / \mathrm{z} 21.02$, corresponding to $\mathrm{H}_{3}{ }^{18} \mathrm{O}^{+}$, was recorded. The $m / z 19.02$ intensity, corresponding to $\mathrm{H}_{3}{ }^{16} \mathrm{O}^{+}$, was determined in the normal manner by multiplying the $\mathrm{m} / \mathrm{z}$ 21.02 signal by 487 . Similarly, the $\mathrm{m} / \mathrm{z} 37.03$ signal intensity, corresponding to $\mathrm{H}_{3}{ }^{16} \mathrm{O}^{+} \cdot \mathrm{H}_{2}{ }^{16} \mathrm{O}$, was not measured directly. Instead, the signal intensity at $\mathrm{m} / \mathrm{z} 39.03\left(\mathrm{H}_{3}{ }^{18} \mathrm{O}^{+} \cdot \mathrm{H}_{2}{ }^{16} \mathrm{O}\right.$ or $\mathrm{H}_{3}{ }^{16} \mathrm{O}^{+} \cdot \mathrm{H}_{2}{ }^{18} \mathrm{O}$ ) was recorded and multiplied by 243 .

Charge Transfer Reaction Mode For the production of $\mathrm{O}_{2}{ }^{+}$, pure oxygen (99.998\% purity, BOC Gases, Manchester, UK) was flowed into the ion source. This leads to the formation of mainly $\mathrm{O}_{2}^{+}$reagent ions (>95\%). Figure 2 shows the $\mathrm{O}_{2}{ }^{+}$ion signal intensity in counts per second (cps) as a function of $E / N$. Once injected into the drift tube, $\mathrm{O}_{2}{ }^{+}$may react with the analyte $M$ via charge transfer, provided that the ionisation energy (IE) of $\mathrm{M}$ is less than that of $\mathrm{O}_{2}\left(\mathrm{IE}\left(\mathrm{O}_{2}\right)=12.07 \mathrm{eV}\right)$. Unlike proton transfer, an exothermic reaction is a necessary but not sufficient criterion for charge transfer to occur, and hence, the reaction rate coefficient may not necessarily be collisional [29]. However, if charge transfer does occur, it may also be either nondissociative (resulting in the singly charged parent ion $\left(\mathrm{M}^{+}\right)$) or dissociative. Fragmentation might be spontaneous upon charge transfer or require additional energy through collisions in the drift tube. $\mathrm{H}_{3} \mathrm{O}^{+}$is also observed when operating the ion source

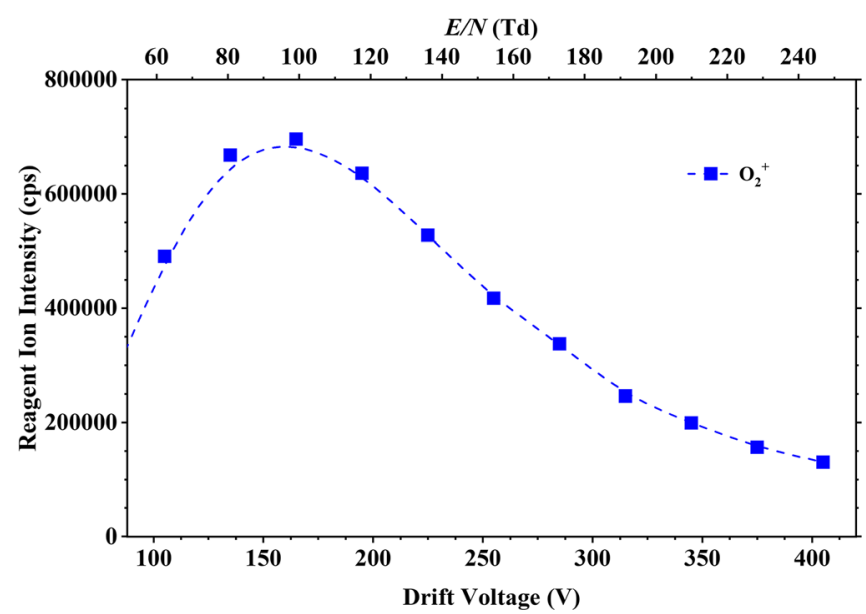

Figure 2. Ion intensities in counts per second (cps) of $\mathrm{O}_{2}{ }^{+}$ recorded at the detector of the KORE SRI-ToF-MS as a function of reduced electric field (approximately 60-250 Td) in oxygen mode. This is due to residual water vapour in the system. However, this can be ignored owing to its signal intensity being approximately $0.1 \%$ of the $\mathrm{O}_{2}{ }^{+}$signal for the experimental conditions used throughout our measurements.

\section{Operational Procedures}

Liquid samples were vapourised making use of a thermal desorption unit (TDU), connected to the inlet of the drift tube via passivated stainless steel (Silconert $($ ). Details of the TDU have been given elsewhere [13]. The TDU, connecting lines and drift tube were operated at a temperature of $150{ }^{\circ} \mathrm{C}$. For this study, oxygen-free nitrogen ( $99.998 \%$ purity, BOC Gases, Manchester, UK) was used as the carrier gas. PTFE swabs (Thermo Fisher Scientific, Cheshire, UK), onto which known quantities of the sample had been deposited, were manually placed into the TDU. Upon closure of the TDU unit, a high force annular "anvil" compressed the PTFE to plastically deform and convert it into a gas tight circular seal around the rim of the swab. At the same time, laboratory air heated to a specified temperature rapidly heats the PTFE and as it passes through carries any thermally desorbed material into the heated inlet line through to the drift (reaction) region. The temporal desorption profile is typically between 10 and $20 \mathrm{~s}$ [13]. For each measurement, one swab was used, which was replicated three times. The results were then averaged, and any background signals were subtracted.

The drift tube pressure was set at 1 mbar, and the glow discharge (for both water vapour and oxygen) was set at 1.4 mbar. The only variable was the operating drift tube voltage, which was adjusted over a range of approximately 100 to $400 \mathrm{~V}$ to provide an appropriate reduced electric field range of about 60-250 Td.

\section{Chemicals}

Individual nitroaniline (2-, 3- and 4-) isomers for this study were purchased from Sigma Aldrich (Cheshire, UK), all of which came with stated purities of at least $98 \%$. At room temperature, nitroanilines are yellowish-orange granulated solids. For the measurements, granules were dissolved in a mixture of MeOH:AcN 1:1 (V/V) (analytical grade) to provide a concentration of approx. $100 \mu \mathrm{g} / \mathrm{mL}$. A volume of $1 \mu \mathrm{L}$ of this solution was deposited onto the swab and left the solvents to evaporate at room temperature for approximately $1 \mathrm{~min}$ before placing the swab into the TDU.

\section{DFT Calculations}

Density functional theory (DFT) calculations have been undertaken to determine the proton affinities and gas-phase basicities of the water monomer, dimer and trimer and the three nitroanilines. These calculations were conducted using Gaussian09W and GaussView05 for Windows [30]. The B3LYP functional with the $6-31+\mathrm{G}(\mathrm{d}, \mathrm{p})$ basis set was used throughout, a combination which has been found to be satisfactory based on our previous work [31, 32]. 


\section{Results}

For this section, only product ions with branching percentages greater than $1 \%$ for any given reduced electric field value are reported. The uncertainty in any branching percentage is approximately $10 \%$. In all cases, only the mass to charge ratio of the lightest isotope is given. However, when calculating the product ion distributions, we considered all of the isotopologues. For the product ion distribution (PID) plots (branching percentages), the voltage applied to the drift tube is shown in the main $x$-axis, and the reduced electric field $E / N$ achieved for that particular voltage is showed in the secondary $x$-axis.

\section{DFT Calculations}

Table 1 presents the calculated proton affinities (PA) and gasphase basicities (GB) for the water monomer, the water dimer, the water trimer and the three nitroanilines. For the nitroaniline isomers, values are provided for the two possible protonation sites, namely on the amino and nitro groups. Aniline and nitrobenzene are also shown for comparison. Table 1 also provides for convenience the ionisation energies of oxygen and the nitroanilines [33].

The proton affinities of the water dimer and trimer are higher than that of the monomer, because of the added stability by sharing the proton with additional waters. The proton affinity of water clusters increases as the number of water molecules increases, but the incremental effect declines as the cluster grows as illustrated in the DFT calculations.

As shown in Table 1, whilst for simpler chemical structures as aniline and nitrobenzene, the aniline's $\mathrm{NH}_{2}$ substituent is much more basic than the $\mathrm{NO}_{2}$ of nitrobenzene, this is not the case in the nitroanilines where both groups are on the ring. The interaction of the nitro group (electron withdrawing effect from the aromatic ring) and the amine group (electron donating effect to the aromatic ring) reverse their basicities, in the order 4-nitroaniline (4-NA) $>2$-NA $>3$-NA. Based on this data, with the exception of the 2-NA where the groups are in close proximity, it is likely that the $\mathrm{NA} \cdot \mathrm{H}^{+}$for the 3 and 4 isomers is a mixture of species.

The DFT calculations show that proton transfer from $\mathrm{H}_{3} \mathrm{O}^{+} \cdot\left(\mathrm{H}_{2} \mathrm{O}\right)_{n}$ ( $n=0$ and 1$)$ to both sites of all three of the nitroanilines is exoergic. $\mathrm{H}_{3} \mathrm{O}^{+} \cdot\left(\mathrm{H}_{2} \mathrm{O}\right)_{2}$ can also proton transfer to the $\mathrm{NO}_{2}$ site of 4-NA.

\section{Fragmentation Patterns and Branching Ratios Studies for Reactions with $\mathrm{H}_{3} \mathrm{O}^{+}$}

2-Nitroaniline Figure 3 shows the product ion distribution (PID) plot for 2-nitroaniline resulting reactions with $\mathrm{H}_{3} \mathrm{O}^{+} \cdot\left(\mathrm{H}_{2} \mathrm{O}\right)_{n}(n=0$ and 1) (see Figure 1) as a function of $E / N$ over the range from 60 to $250 \mathrm{Td}$. The protonated parent, [2-NA $\mathrm{H}]^{+}$, at $m / z 139.05$ is the most intense product ion until about $220 \mathrm{Td}$, after which fragment product ions dominate. Fragment product ions begin to appear at about $150 \mathrm{Td}$, starting with at $m / z 121.04$ (resulting from the loss of a water molecule from the protonated parent, [2-NA- $\left.\mathrm{H}_{2} \mathrm{O}\right] \mathrm{H}^{+}$), and which becomes dominant above about $220 \mathrm{Td}$. Other fragment product ions are observed with increasing $E / N$, namely $\mathrm{m} / \mathrm{z} 93.06$ (assigned to the loss of a nitro group from the protonated parent, leading to a $\mathrm{C}_{6} \mathrm{H}_{7} \mathrm{~N}^{+}$ion) and $m / z 91.04$ (caused by the loss of a nitro group followed by the sequential loss of a hydrogen molecule, leading to $\mathrm{C}_{6} \mathrm{H}_{5} \mathrm{~N}^{+}$ion). At low reduced electric fields (less than about $120 \mathrm{Td}$ ), a product ion is observed at $m / z 157.06$, which is simply $2-\mathrm{NAH}^{+} \cdot \mathrm{H}_{2} \mathrm{O}$, resulting from a third body association reaction of the protonated parent with water. Its intensity increases as the $E / N$ decreases because of reduced collisional induced dissociation.

Figure 4 shows two overlaid mass spectra at two different $E / N$ values for 2-nitroaniline, exemplifying the difference in performance for the instrument-similar plots (not shown) were found for the rest of the samples and for oxygen chemistry.

3-Nitroaniline Figure 5 shows the PID plot for 3nitroaniline resulting from its reaction with $\mathrm{H}_{3} \mathrm{O}^{+} \cdot\left(\mathrm{H}_{2} \mathrm{O}\right)_{n}$

Table 1. Proton Affinities (PA), Gas-Phase Basicities (GB) and Ionisation Energies (IE) for Nitroaniline (NA) Isomers. The PA and GB Values Have Been Calculated Using the B3LYP Functional and the 6-31+G(d,p) Basis Set at $298 \mathrm{~K} . \Delta H_{298}$ and $\Delta G_{298}$ Refer to the Enthalpies and Free Energies for the Addition of Water to the Protonated Species. For Convenience, the Ionisation Energies of $\mathrm{O}_{2}$ and the Three Nitroanilines Are Also Provided

\begin{tabular}{|c|c|c|c|c|c|c|}
\hline Chemical & Site & $\mathrm{PA}^{\mathrm{a}}$ & $\mathrm{GB}^{\mathrm{a}}$ & $\Delta H_{298}{ }^{\mathrm{a}}$ & $\Delta G_{298}{ }^{\mathrm{a}}$ & $\operatorname{IE}(\mathrm{eV})^{\mathrm{b}}$ \\
\hline Water & & 684 & 653 & & & \\
\hline Water dimer & & 842 & 777 & & & \\
\hline Water trimer & & 937 & 841 & & & \\
\hline $\mathrm{O}_{2}$ & & & & & & $12.07[34]$ \\
\hline \multirow[t]{2}{*}{$2-\mathrm{NA}$} & $\mathrm{NH}_{2}$ & 840 & 806 & -69 & -37 & 8.27 \\
\hline & $\mathrm{NO}_{2}$ & 858 & 824 & -76 & -43 & \\
\hline \multirow[t]{2}{*}{ 3-NA } & $\mathrm{NH}_{2}$ & 824 & 796 & -78 & -43 & 8.31 \\
\hline & $\mathrm{NO}_{2}$ & 830 & 800 & -84 & -51 & \\
\hline \multirow[t]{2}{*}{ 4-NA } & $\mathrm{NH}_{2}$ & 810 & 784 & -78 & -43 & 8.34 \\
\hline & $\mathrm{NO}_{2}$ & 879 & 847 & -73 & -39 & \\
\hline Aniline & $\mathrm{NH}_{2}$ & 874 & 846 & -72 & -40 & \\
\hline Nitrobenzene & $\mathrm{NO}_{2}$ & 806 & 775 & -90 & -55 & \\
\hline
\end{tabular}

${ }^{\mathrm{a}}$ Thermochemical data expressed in kilojoules per mole

${ }^{\mathrm{b}}$ Ionisation energies (in eV) have been taken from NIST database [33] 


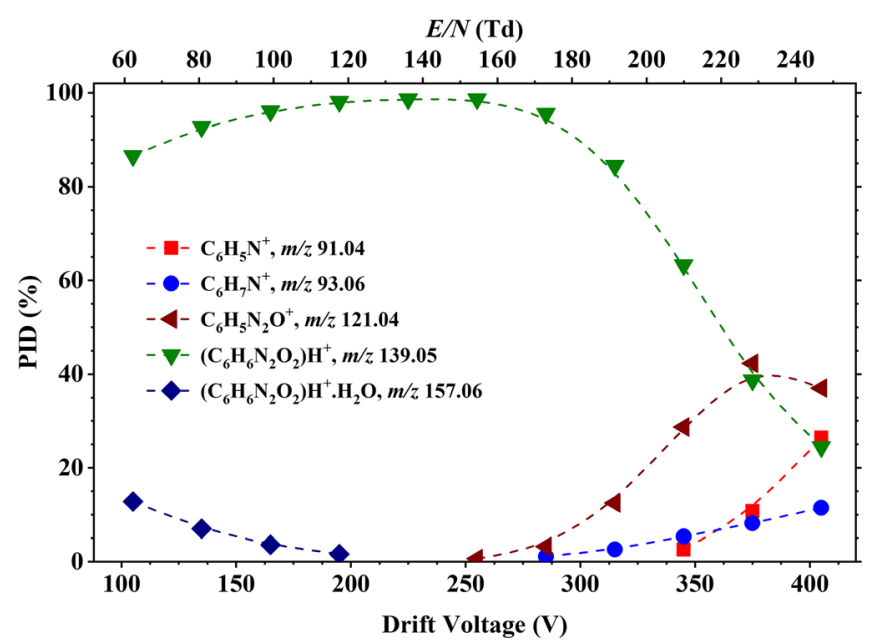

Figure 3. Percentage product ion distribution (PID in \%) resulting from the reaction of 2-nitroaniline with $\mathrm{H}_{3} \mathrm{O}^{+} \cdot\left(\mathrm{H}_{2} \mathrm{O}\right)_{n}$ ( $n=0$ and 1) as a function of the reduced electric field from 60 to $250 \mathrm{Td}$

$(n=0$ and 1$)$ as a function of the reduced electric field $E / N$ for the range from 20 to $250 \mathrm{Td}$. Similar to the results obtained for 2-NA, the protonated parent [3$\mathrm{NA} \cdot \mathrm{H}]+$ is the dominant product ion up to about $220 \mathrm{Td}$. However, unlike 2-NA, much more association of the protonated parent with water is observed at low reduced electric fields $(<140 \mathrm{Td})$, under identical operational (reduced electric field and humidity) conditions. At $60 \mathrm{Td}, 3-\mathrm{NAH}^{+} \cdot \mathrm{H}_{2} \mathrm{O}$ has approximately the same branching percentage as the protonated parent.

Above ca. $230 \mathrm{Td}$, the fragment product ion $\mathrm{C}_{6} \mathrm{H}_{7} \mathrm{~N}^{+}$ dominates. Another product ion, starting at an $E / N$ value of approximately $190 \mathrm{Td}$, is observed at $\mathrm{m} / \mathrm{z} 109.05$. This is considered to result from the loss of NO from the protonated parent leading to $\mathrm{C}_{6} \mathrm{H}_{7} \mathrm{NO}^{+}$[35]. This product ion was not observed for 2-nitroaniline.

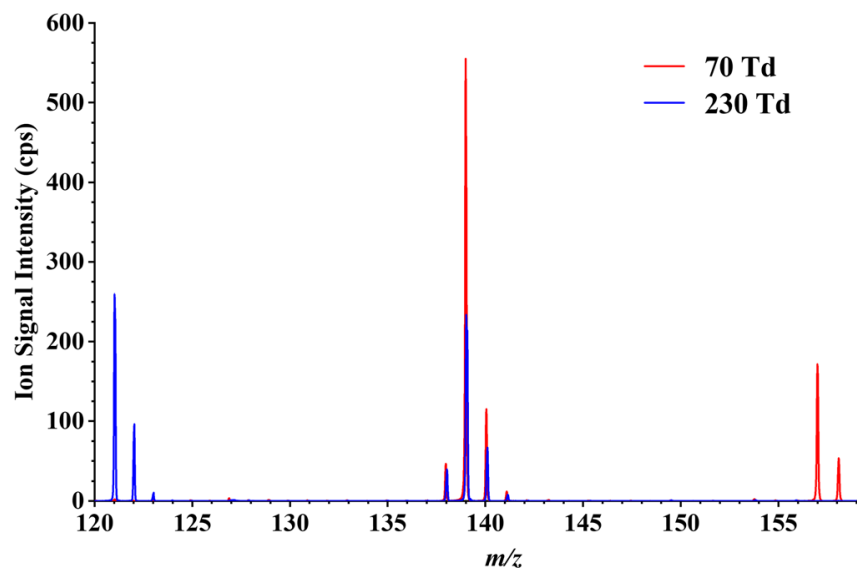

Figure 4. Overlaid mass spectra for 2-nitroaniline at 70 and $230 \mathrm{Td}$. This figure illustrates the clear difference in ion signal intensities for $m / z 121.04,139.05$ and 157.06 upon the reduced electric field applied to the DT of the instrument

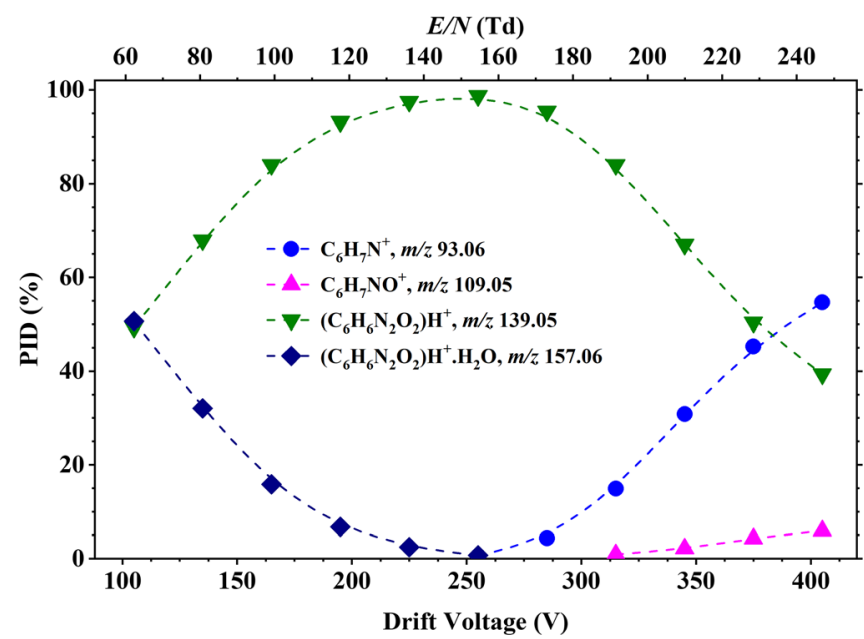

Figure 5. Percentage product ion distribution resulting from the reaction of 3-nitroaniline with $\mathrm{H}_{3} \mathrm{O}^{+} \cdot\left(\mathrm{H}_{2} \mathrm{O}\right)_{n}(n=0$ and 1$)$ as a function of the reduced electric field from 60 to $250 \mathrm{Td}$

4-Nitroaniline Figure 6 presents the PID for the reaction of 4nitroaniline with $\mathrm{H}_{3} \mathrm{O}^{+} \cdot\left(\mathrm{H}_{2} \mathrm{O}\right)_{n}(n=0$ and 1$)$ as a function of the reduced electric field $E / N$ for the range from 60 to $250 \mathrm{Td}$. For this isomer, the protonated parent, $[4-\mathrm{NA} \cdot \mathrm{H}]^{+}$, dominates throughout the whole $E / N$ range. Little fragmentation occurs, with only one product ion being observed at $\mathrm{m} / \mathrm{z} 93.06$ (corresponding to the loss of a nitro group from the protonated parent molecule) above about $160 \mathrm{Td}$. Three-body association of the protonated parent with water is also observed at $\mathrm{m} / \mathrm{z} 157.06$, with a similar intensity to that found for 2-NA.

Thus, we find that protonated 3-NA solvates more readily than do protonated 2-NA and 4-NA, and this merits some discussion. Table 1 shows that the $\Delta G_{298}$ for the association of water to protonated 2 and 4-NA is $43 \mathrm{~kJ} \mathrm{~mol}^{-1}$, whereas the $\Delta G_{298}$ for association of water to protonated 3-NA is $51 \mathrm{~kJ} \mathrm{~mol}$ ${ }^{-1}$. Whilst $8 \mathrm{~kJ} \mathrm{~mol}^{-1}$ may not seem a great difference, when converted into equilibrium constants, at the operating

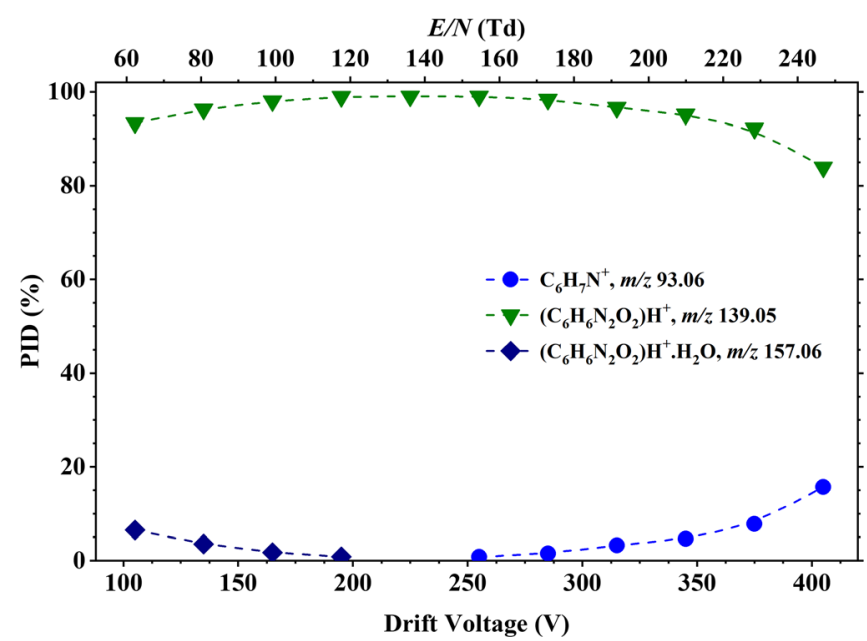

Figure 6. Percentage product ion distribution resulting from the reaction of 4-nitroaniline with $\mathrm{H}_{3} \mathrm{O}^{+} \cdot\left(\mathrm{H}_{2} \mathrm{O}\right)_{n}(n=0,1$ and 2) as a function of the reduced electric field from 60 to $250 \mathrm{Td}$ 
temperature of the drift tube $(423 \mathrm{~K}), 3-\mathrm{NAH}^{+}$binds water approximately ten times better than $2-\mathrm{NAH}^{+}$and $4-\mathrm{NAH}^{+}$.

In comparison to the product ion fragmentation patterns found for 2- and 3-NA, the 4-NA isomer is quite different. This is a direct effect of the para position for the functional groups in the aromatic ring. The amine and nitro substituents are far off from each other, and therefore, there is no option for an intermediate transition state where a ring is formed prior to leading to the final product ion. This is consistent with chemical ionisation work reported for the nitroarenes with electronreleasing substituents [36].

\section{Fragmentation Patterns and Branching Percentage Studies for Reactions with $\mathrm{O}_{2}{ }^{+}$}

2-Nitroaniline Figure 7 presents a summary of the results for the reaction of $\mathrm{O}_{2}^{+}$with 2-NA as a function of reduced electric field. The parent ion at $m / z$ 138.04, [2-NA] $]^{+}$, resulting from non-dissociative charge transfer, dominates up to about $230 \mathrm{Td}$. Its abundance decreases as the reduced electric field increases, and at $E / N$, above ca. $230 \mathrm{Td}, m / z 80.05$ (assigned to the product ion $\mathrm{C}_{5} \mathrm{H}_{6} \mathrm{~N}^{+}$) becomes dominant. Other product ions, resulting from dissociative charge transfer, are observed at $m / z 65.04\left(\mathrm{C}_{5} \mathrm{H}_{5}{ }^{+}\right), m / z 92.07\left(\mathrm{C}_{6} \mathrm{H}_{6} \mathrm{~N}^{+}\right)\left(\right.$loss of $\left.\mathrm{NO}_{2}\right), \mathrm{m} / z$ $108.04\left(\mathrm{C}_{6} \mathrm{H}_{6} \mathrm{NO}^{+}\right)$(loss of NO) and $m / z 121.04\left(\mathrm{C}_{6} \mathrm{H}_{5} \mathrm{~N}_{2} \mathrm{O}^{+}\right.$) (loss of $\mathrm{OH}) . \mathrm{C}_{6} \mathrm{H}_{5} \mathrm{~N}_{2} \mathrm{O}^{+}$was not observed in any of the other isomers.

3-Nitroaniline For 3-NA, a very similar fragmentation product ion pattern found for that of 2-NA is observed, as shown in Figure 8. Products ions are observed at $m / z 65.04\left(\mathrm{C}_{5} \mathrm{H}_{5}{ }^{+}\right)$, $80.05\left(\mathrm{C}_{5} \mathrm{H}_{6} \mathrm{~N}^{+}\right), m / z 92.07\left(\mathrm{C}_{6} \mathrm{H}_{6} \mathrm{~N}^{+}\right), m / z 108.04\left(\mathrm{C}_{6} \mathrm{H}_{6} \mathrm{NO}^{+}\right)$ and $m / z$ 138.04, [3-NA] $]^{+}$, but with slight differences in their intensities at very high $E / N$ values. For 3-NA, the parent ion at $\mathrm{m} / \mathrm{z}$ 138.04, [3-NA] $]^{+}$dominates for most of the reduced electric field investigated. But by about $240 \mathrm{~m} / z, 80.05\left(\mathrm{C}_{5} \mathrm{H}_{6} \mathrm{~N}^{+}\right)$

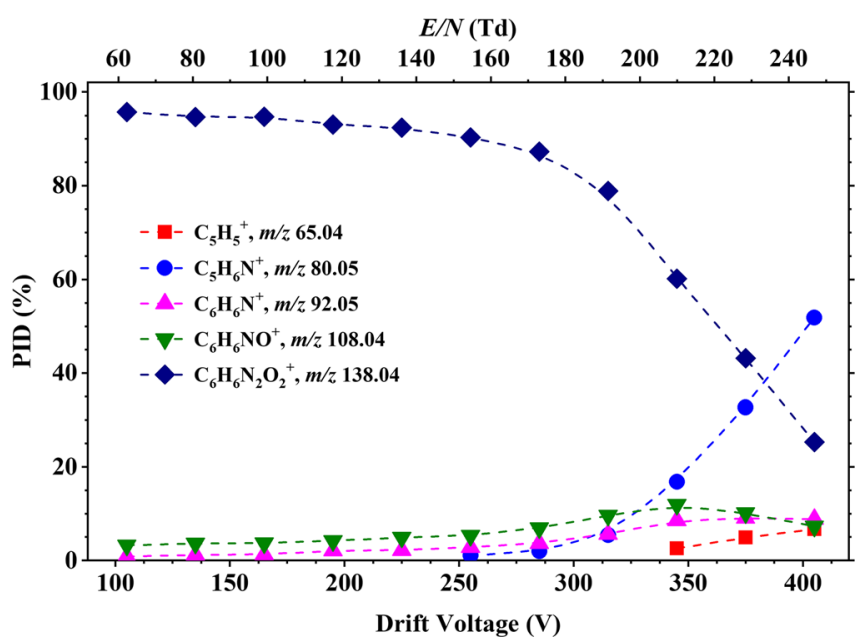

Figure 7. Percentage product ion distribution resulting from the reaction of 2-nitroaniline with $\mathrm{O}_{2}{ }^{+}$as a function of the reduced electric field from 60 to $250 \mathrm{Td}$

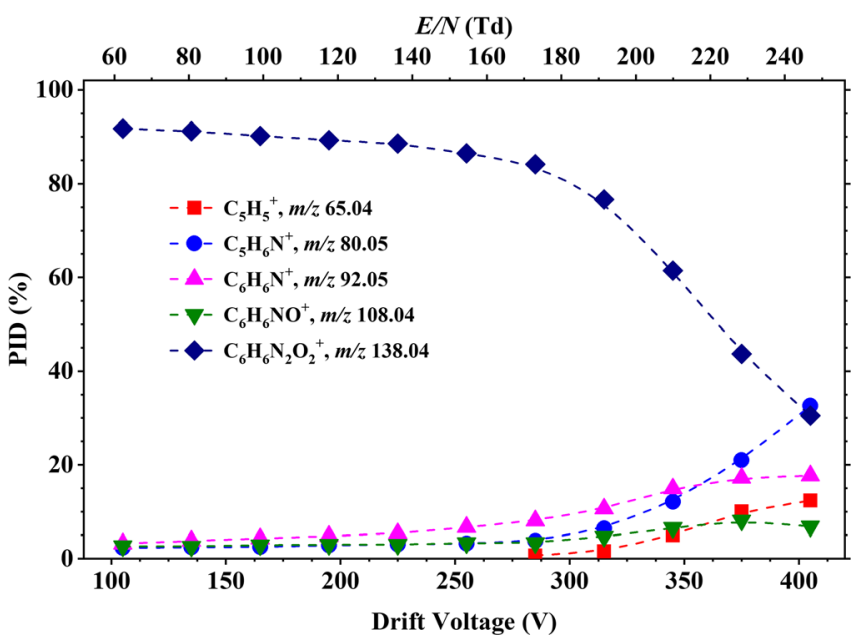

Figure 8. Percentage product ion distribution resulting from the reaction of 3-nitroaniline with $\mathrm{O}_{2}{ }^{+}$as a function of the reduced electric field in the range from 60 to $250 \mathrm{Td}$

becomes dominant. A clear difference is the intensity for the product ion at $m / z 92.05\left(\mathrm{C}_{6} \mathrm{H}_{6} \mathrm{~N}^{+}\right)$, going up to ca. $15 \%$ (compared to only ca. 5\% for 2-NA) and at $\mathrm{m} / z 65.04$ $\left(\mathrm{C}_{5} \mathrm{H}_{5}^{+}\right)$(ca. $12 \%$ for 3-NA compared to ca. $6 \%$ for $2-\mathrm{NA}$ ).

4-Nitroaniline The product ion fragmentation pattern for 4NA, as shown in Figure 9, is very different from that observed for the other two isomers, with a simpler product ion distribution being observed, having only three product ions. This is a direct consequence of the para position for the substituents in the aromatic ring. The parent ion at $m / z$ 138.04, [4-NA ${ }^{+}$, dominates from $60 \mathrm{Td}$ up to ca. $190 \mathrm{Td}$, after which the product ion at $m / z 108.04\left(\mathrm{C}_{6} \mathrm{H}_{6} \mathrm{NO}^{+}\right)$becomes dominant. For $E / N$ values above $190 \mathrm{Td}$, another fragment ion at $\mathrm{m} / \mathrm{z} 80.05$ $\left(\mathrm{C}_{5} \mathrm{H}_{6} \mathrm{~N}^{+}\right)$becomes relevant, having a maximum intensity of ca. $30 \%$ at an $E / N$ value of $250 \mathrm{Td}$.

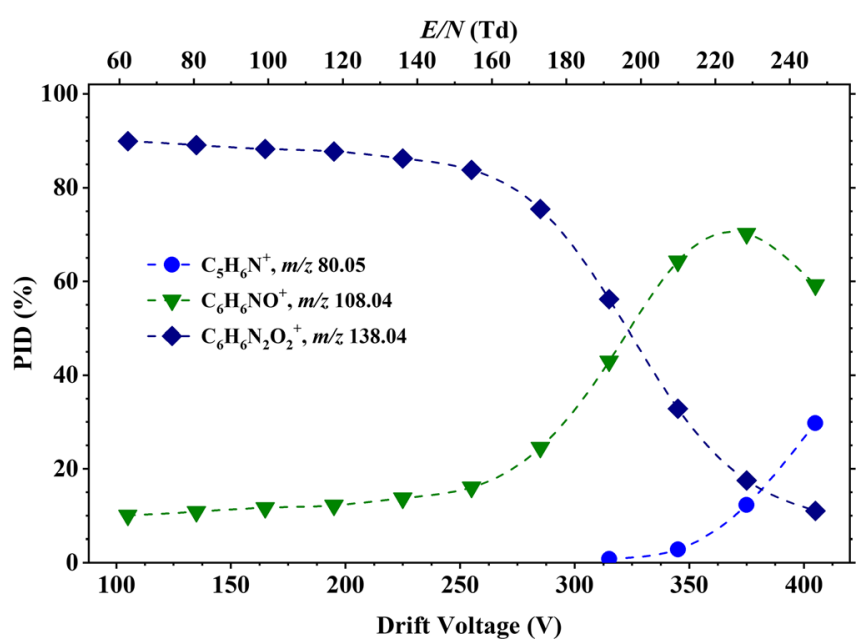

Figure 9. Percentage product ion distribution resulting from the reaction of 4-nitroaniline with $\mathrm{O}_{2}{ }^{+}$as a function of the reduced electric field in the range from 60 to $250 \mathrm{Td}$ 


\section{Conclusions}

This work reports the product ions from the reaction of 2-, 3and 4-nitroaniline isomers with $\mathrm{H}_{3} \mathrm{O}^{+}$and $\mathrm{O}_{2}{ }^{+}$as a function of the reduced electric field in a SRI-ToF-MS. We have shown that selective reagent ion mass spectrometry, using either water or oxygen as reagent gases, can be used to detect nitroaniline isomers with good selectivity. The most abundant product ion for all the isomers for the reactions with $\mathrm{H}_{3} \mathrm{O}^{+}$is the protonated parent at $\mathrm{m} / \mathrm{z} 139.05$ over an extended reduced electric field range. For the reactions with $\mathrm{O}_{2}{ }^{+}$, non-dissociative charge transfer results in the parent ion at $\mathrm{m} / \mathrm{z} 138.04$ being the most abundant product ion. However, relative ion abundances are different for each reagent ion. 2- and 3-NA show very similar fragmentation patterns with $\mathrm{O}_{2}{ }^{+}$, whilst with $\mathrm{H}_{3} \mathrm{O}^{+}$, 2-NA shows smaller water clustering at low $E / N$ and its fragment product ions become dominant at a lower $E / N$ than found for 3NA. 4-NA shows less fragmentation with $\mathrm{H}_{3} \mathrm{O}^{+}$, and for the reaction with $\mathrm{O}_{2}{ }^{+}$, a distinctive fragment ion is observed at $\mathrm{m} / \mathrm{z}$ 108.04, which becomes dominant above about $190 \mathrm{Td}$. The presence or absence of this product ion at $\mathrm{m} / \mathrm{z} 108.04$ easily allows for reliable identification of the 4-NA isomer.

This study demonstrates how it is possible to distinguish isomers based on the manipulation of the ion/molecule chemistry and/or using different reagent ions that favour different ionisation mechanisms.

\section{Acknowledgements}

We thank the Marie Skłodowska-Curie Actions Innovative Training Network: Ion-Molecule Processes for Analytical Chemistry Technologies (IMPACT) (www.impact-h2020itn. com) which has supported this research through the European Commission's HORIZON 2020 Programme under Grant Agreement Number 674911. DOL is an Early Stage Researcher on IMPACT. We also thank Dr. Peter Watts (a member of the Molecular Physics Group, School of Physics and Astronomy, University of Birmingham, UK) for undertaking the DFT calculations presented in this paper. The authors also thank Mahroz Mirzahekmati for producing the graphical abstract.

\section{Open Access}

This article is distributed under the terms of the Creative Commons Attribution 4.0 International License (http:// creativecommons.org/licenses/by/4.0/), which permits unrestricted use, distribution, and reproduction in any medium, provided you give appropriate credit to the original author(s) and the source, provide a link to the Creative Commons license, and indicate if changes were made.

\section{References}

1. Ellis, A. M., Mayhew, C. A.: Proton Transfer Reaction Mass Spectrometry: Principles and Applications. 1st ed. Wiley, p 336 (2014)
2. Biasioli, F., Yeretzian, C., Märk, T.D., Dewulf, J., Van Langenhove, H.: Direct-injection mass spectrometry adds the time dimension to (B) VOC analysis. TrAC Trends Anal. Chem. 30(7), 1003-1017 (2011)

3. Mayhew, C.A., Sulzer, P., Petersson, F., Haidacher, S., Jordan, A., Märk, L., Watts, P., Märk, T.D.: Applications of proton transfer reaction timeof-flight mass spectrometry for the sensitive and rapid real-time detection of solid high explosives. Int. J. Mass Spectrom. 289(1), 58-63 (2010)

4. Sulzer, P., Petersson, F., Agarwal, B., Becker, K.H., Jürschik, S., Märk, T.D., Perry, D., Watts, P., Mayhew, C.A.: Proton transfer reaction mass spectrometry and the unambiguous real-time detection of 2,4,6 trinitrotoluene. Anal. Chem. 84(9), 4161-4166 (2012)

5. Kassebacher, T., Sulzer, P., Jürschik, S., Hartungen, E., Jordan, A., Edtbauer, A., Feil, S., Hanel, G., Jaksch, S., Märk, L., Mayhew, C.A., Märk, T.D.: Investigations of chemical warfare agents and toxic industrial compounds with proton-transfer-reaction mass spectrometry for a realtime threat monitoring scenario. Rapid Commun. Mass Spectrom. 27(2), 325-332 (2013)

6. Fernández del Río, R., O’Hara, M.E., Holt, A., Pemberton, P., Shah, T., Whitehouse, T., Mayhew, C.A.: Volatile biomarkers in breath associated with liver cirrhosis - comparisons of pre- and post-liver transplant breath samples. EBioMedicine. 2(9), 1243-1250 (2015)

7. Trefz, P., Schubert, J.K., Miekisch, W.: Effects of humidity, $\mathrm{CO} 2$ and $\mathrm{O} 2$ on real-time quantitation of breath biomarkers by means of PTR-ToFMS. J. Breath. Res. 12(2), 026016 (2018)

8. Herbig, J., Beauchamp, J.: Towards standardization in the analysis of breath gas volatiles. J. Breath. Res. 8(3), 037101 (2014)

9. Ruzsányi, V., Kalapos, M.P., Schmidl, C., Karall, D., Scholl-Bürgi, S., Baumann, M.: Breath profiles of children on ketogenic therapy. J. Breath. Res. 12(3), 036021 (2018)

10. Agarwal, B., Petersson, F., Jürschik, S., Sulzer, P., Jordan, A., Märk, T.D., Watts, P., Mayhew, C.A.: Use of proton transfer reaction time-offlight mass spectrometry for the analytical detection of illicit and controlled prescription drugs at room temperature via direct headspace sampling. Anal. Bioanal. Chem. 400(8), 2631-2639 (2011)

11. Lanza, M., Acton, W.J., Sulzer, P., Breiev, K., Jürschik, S., Jordan, A., Hartungen, E., Hanel, G., Märk, L., Märk, T.D., Mayhew, C.A.: Selective reagent ionisation-time of flight-mass spectrometry: a rapid technology for the novel analysis of blends of new psychoactive substances. J. Mass Spectrom. 50(2), 427-431 (2015)

12. Critchley, A., Elliott, T., Harrison, G., Mayhew, C., Thompson, J., Worthington, T.: The proton transfer reaction mass spectrometer and its use in medical science: applications to drug assays and the monitoring of bacteria. Int. J. Mass Spectrom. 239(2-3), 235-241 (2004)

13. González-Méndez, R., Reich, D.F., Mullock, S.J., Corlett, C.A., Mayhew, C.A.: Development and use of a thermal desorption unit and proton transfer reaction mass spectrometry for trace explosive detection: determination of the instrumental limits of detection and an investigation of memory effects. Int. J. Mass Spectrom. 385, 13-18 (2015)

14. Shen, C., Li, J., Han, H., Wang, H., Jiang, H., Chu, Y.: Triacetone triperoxide detection using low reduced-field proton transfer reaction mass spectrometer. Int. J. Mass Spectrom. 285(1-2), 100-103 (2009)

15. Jürschik, S., Sulzer, P., Petersson, F., Mayhew, C.A., Jordan, A., Agarwal, B., Haidacher, S., Seehauser, H., Becker, K., Märk, T.D.: Proton transfer reaction mass spectrometry for the sensitive and rapid real-time detection of solid high explosives in air and water. Anal. Bioanal. Chem. 398(7-8), 2813-2820 (2010)

16. Sulzer, P., Agarwal, B., Jürschik, S., Lanza, M., Jordan, A., Hartungen, E., Hanel, G., Märk, L., Märk, T.D., González-Méndez, R., Watts, P., Mayhew, C.A.: Applications of switching reagent ions in proton transfer reaction mass spectrometric instruments for the improved selectivity of explosive compounds. Int. J. Mass Spectrom. 354-355(0), 123-128 (2013)

17. Agarwal, B., González-Méndez, R., Lanza, M., Sulzer, P., Märk, T.D., Thomas, N., Mayhew, C.A.: Sensitivity and selectivity of switchable reagent ion soft chemical ionization mass spectrometry for the detection of picric acid. J. Phys. Chem. A. 118(37), 8229-8236 (2014)

18. González-Méndez, R., Watts, P., Olivenza-León, D., Reich, D.F., Mullock, S.J., Corlett, C.A., Cairns, S., Hickey, P., Brookes, M., Mayhew, C.A.: Enhancement of compound selectivity using a radio frequency ion-funnel proton transfer reaction mass spectrometer: improved specificity for explosive compounds. Anal. Chem. 88(21), 10624-10630 (2016) 
19. González-Méndez, R.: Development and Applications of Proton Transfer Reaction-Mass Spectrometry for Homeland Security: Trace Detection of Explosives. PhD, University of Birmingham, (2017)

20. González-Méndez, R., Watts, P., Reich, D.F., Mullock, S.J., Cairns, S., Hickey, P., Brookes, M., Mayhew, C.A.: Use of rapid reduced electric field switching to enhance compound specificity for proton transfer reaction-mass spectrometry. Anal. Chem. 90(9), 5664-5670 (2018)

21. Petersson, F., Sulzer, P., Mayhew, C.A., Watts, P., Jordan, A., Märk, L., Märk, T.D.: Real-time trace detection and identification of chemical warfare agent simulants using recent advances in proton transfer reaction time-of-flight mass spectrometry. Rapid Commun. Mass Spectrom. 23(23), 3875-3880 (2009)

22. González-Méndez, R., Mayhew, C.A.: Applications of direct injection soft chemical ionisation-mass spectrometry for the detection of pre-blast smokeless powder organic additives. J. Am. Soc. Mass Spectrom. 30(4), 615-624 (2019)

23. Barber, S., Blake, R.S., White, I.R., Monks, P.S., Reich, F., Mullock, S. Ellis, A.M.: Increased sensitivity in proton transfer reaction mass spectrometry by incorporation of a radio frequency ion funnel. Anal. Chem. 84(12), 5387-5391 (2012)

24. Lanza, M., Acton, W.J., Jürschik, S., Sulzer, P., Breiev, K., Jordan, A., Hartungen, E., Hanel, G., Märk, L., Mayhew, C.A., Märk, T.D.: Distinguishing two isomeric mephedrone substitutes with selective reagent ionisation mass spectrometry (SRI-MS). J. Mass Spectrom. 48(9), 1015-1018 (2013)

25. Yuan, H.; Li, D.; Liu, Y.; Xu, X.; Xiong, C.: Nitrogen-doped carbon dots from plant cytoplasm as selective and sensitive fluorescent probes for detecting p-nitroaniline in both aqueous and soil systems. Analyst. 140(5), 1428-1431 (2015)
26. Lu, X., Yang, Y., Zeng, Y., Li, L., Wu, X.: Rapid and reliable determination of $\mathrm{p}$-nitroaniline in wastewater by molecularly imprinted fluorescent polymeric ionic liquid microspheres. Biosens. Bioelectron. 99, 47$55(2018)$

27. Booth, G.: Ullmann's encyclopedia of industrial chemistry. Ref. Serv. Rev. 16(4), 31-34 (2007)

28. Blake, R.S., Monks, P.S., Ellis, A.M.: Proton-transfer reaction mass spectrometry. Chem. Rev. 109(3), 861-896 (2009)

29. Jarvis, G., Kennedy, R., Mayhew, C., Tuckett, R.P.: Charge transfer from neutral perfluorocarbons to various cations: long-range versus short-range reaction mechanisms. Int. J. Mass Spectrom. 202(1-3), 323-343 (2000)

30. Frisch, M.; Trucks, G.; Schlegel, H.; Scuseria, G.; Robb, M.; Cheeseman, J.; Scalmani, G.; Barone, V.; Mennucci, B.; Petersson, G.: Gaussian 09, revision A. 1. Gaussian Inc., Wallingford (2009)

31. González-Méndez, R., Watts, P., Howse, D.C., Procino, I., McIntyre, H., Mayhew, C.A.: Ion mobility studies on the negative ion-molecule chemistry of isoflurane and enflurane. J. Am. Soc. Mass Spectrom. 28(5), 939946 (2017)

32. González-Méndez, R., Watts, P., Howse, D.C., Procino, I., McIntyre, H., Mayhew, C.A.: Ion mobility studies on the negative ion-molecule chemistry of pentachloroethane. Int. J. Mass Spectrom. 417, 16-21 (2017)

33. P.J. Linstrom, W. G. M., Eds., NIST Chemistry WebBook. (2015)

34. Tonkyn, R.G., Winniczek, J.W., White, M.G.: Rotationally resolved photoionization of $\mathrm{O} 2+$ near threshold. Chem. Phys. Lett. 164(2-3), 137-142 (1989)

35. Beynon, J., Lester, G., Williams, A.: Some specific molecular rearrangements in the mass spectra of organic compounds. J. Phys. Chem. 63(11), 1861-1868 (1959)

36. Harrison, A.G., Kallury, R.K.M.R.: Chemical ionization mass spectra of mononitroarenes. Org. Mass Spectrom. 15(6), 284-288 (1980) 